\title{
O trabalho docente frente as relações étnico-raciais no ensino
} fundamental

DOI: 10.47224/revistamaster.v6i11.159

\author{
Danilo Faria de Moura \\ Maria Luiza de Borba Alves \\ Andreia Regina da Silva \\ Juliana de Sousa Faria \\ Natália Medeiros de Almeida Rodovalho \\ Natalia Silva \\ Nayara da Silva Fernandes \\ Ordalha Jordana da Silva Reis
}

e-mail: danilofmoura@yahoo.com.br

\section{Resumo}

A escola, por meio de seu representante em sala de aula, o docente, tem a responsabilidade de formar o seu aluno para o exercício da cidadania e essa tarefa pode perfeitamente ser realizada amparada na história de seu país. O objetivo deste artigo é propor meios para docentes buscarem embasamento na preparação de suas aulas garantindo processos de ensino e aprendizagem efetivos a seus alunos no que se refere à temática das relações étnico-raciais. As pesquisas foram desenvolvidas por meio da Metodologia da Problematização do Arco de Maguerez e o aporte teórico realizado com a utilização de uma pesquisa bibliográfica. A problemática, tornou-se visível através do instrumento de questionário aplicado a professoras de escolas públicas da cidade de Araguari - MG, em que registrou-se como maior porcentagem negativa relacionada às relações étnico-raciais as respostas à alternativa "trabalho em desenvolvimento na minha escola", o que gerou grande inquietação e motivou indagar sobre como é desenvolvido esse tópico, quais os gatilhos utilizados para iniciar a abordagem, objetivo e por quanto tempo perdura no decorrer do ano letivo. Concluiu-se que os fazeres do docente relacionados à temática, tanto na sua prática em sala de aula como na formação continuada, devem se fazer presentes em sua rotina de atuação profissional.

Palavras-chave: Ensino; Aprendizagem; Relações Étnico-Raciais; Cidadania.

\begin{abstract}
The school, through its representative within the classroom, the teacher, has the responsibility to coach its students for the exercise of citizenship and this task can perfectly be administered supported the history of their country. The aim of this text is to propose ways for teachers to hunt foundation within the preparation of their classes, ensuring effective teaching and learning processes for his or her students with reference to the theme of ethnic-racial relations. The researches were developed through the Maguerez Arch Problematization Methodology and therefore the theoretical support administered employing a bibliographical research. the matter was made visible through the questionnaire instrument applied to public school teachers within the city of Araguari - MG, during which the very best negative percentage associated with ethnic-racial relations was recorded as answers to the choice "work in development in my school", which generated great concern and motivated us to inquire about how this subject is developed, which triggers are wont to initiate the approach, objective and the way long it lasts throughout the varsity year. It had been concluded that the doings of teachers associated with the theme, both within their practice in the classroom and in continuing education, should be present in their professional performance routine.
\end{abstract}

Keywords: $\quad$ Teaching; Learning; Ethnic-Racial Relations; Citizenship. 


\section{INTRODUÇÃO}

O presente artigo é decorrente de atividades elaboradas no Curso de Pedagogia relacionadas ao componente curricular "Projeto Integrador VII Educação das Relações Étnico-raciais e história e cultura afro-brasileira, africana e indígena", do sexto e sétimo períodos, do primeiro semestre de 2020 .

As pesquisas aqui relatadas foram desenvolvidas por meio da Metodologia da Problematização do Arco de Maguerez e vivenciada tendo como marco norteador a seguinte temática: a abordagem da cultura afro-brasileira no ensino fundamental das escolas públicas na cidade de Araguari/MG. Utilizouse de um questionário respondido por docentes para a observação da realidade e posteriormente da revisão bibliográfica para o embasamento teórico dos assuntos apresentados.

Dos resultados advindos da aplicação do questionário, no qual pontuou-se o propósito de minimizar a insipiência de docentes em trabalhar de forma contínua o tema de étnicas raciais e história e cultura afro-brasileira em suas aulas, analisou-se sobre a propagação dessa cultura em sala de aula e como tornou-se um tema de urgência, visto que muitos educadores não usufruíram formação para esse conteúdo, desconhecendo a importância da trajetória que marcou e deixou grande herança para o Brasil, sentindo-se impossibilitados de trabalhar a narrativa de maneira coerente sem folclorismos.

O desconhecimento das experiências de ser, viver, pensar e realizar de índios, de descendentes de africanos, de europeus, de asiáticos, faz com que a educação seja disseminada como se a sociedade fosse mono cultural. Isto faz com que se torne difícil corrigir a ilusão da democracia racial, de vencer determinações do sistema de mundo centrado em cosmovisão representativa de uma única raiz étnicoracial, impedindo a população de ter acesso a conhecimentos de diferentes origens étnico-raciais, ensinando um elenco de conteúdos tido como o mais perfeito e completo que a humanidade já teria produzido. (SILVA, 2007, p. 501)

A escola, por meio de seu representante em sala de aula - o docente, tem a responsabilidade de formar o seu aluno para o exercício da cidadania e essa tarefa pode perfeitamente ser realizada amparada na história, para que compreendam a diversidade partindo de sua origem e evolução, e a partir desse contexto internalizem a importância das raças e suas culturas para a formação do povo brasileiro, tornando fator de exclusão de qualquer tipo de discriminação perante a cultura a que são pertencentes.

Para superar a tudo isto, precisamos ultrapassar estereótipos, extinguir preconceitos, e como disse Senghor, em um de seus poemas, proceder a uma "desintoxicação semântica", isto é, redefinir termos e conceitos, por exemplo, no nosso caso do campo educacional, a começar por educação, aprender, ensinar, saber, educar, educar-se. (SILVA, 2007, p. 501)

Levando-se em consideração os aspectos mencionados, será apresentado na sequência os desígnios das relações étnico-raciais história e cultura afro-brasileira, africana e indígena na educação através da observação da realidade, as justificativas, a delimitação da problemática, os pontos-chave elencados, o desenvolvimento a partir da teorização, as hipóteses de solução, os relatos de aplicação à realidade e as considerações finais.

\section{OBSERVAÇÃO DA REALIDADE}

Exigências éticas, epistemológicas,
pedagógicas desencadeadas pela
implantação das Diretrizes Curriculares
Nacionais para o Ensino de História e
Cultura Afro-Brasileira e Africana (BRASIL,
2004a, 2004b) instigam conhecer,
esquadrinhar condições, contextos, redes
de relações em que as mulheres e os
homens, ao longo da história da nação, vêm
aprendendo e ensinando a exercer
cidadania. (SILVA, 2007, p. 489)

É de conhecimento geral que o mundo está atravessando um período muito delicado, por eventualidade da COVID-19, e por mais que as pessoas se sintam coagidas pelo isolamento social, se fez necessário modificar velhos hábitos e seguir com as atividades cotidianas, e a oportunidade que é oferecida frente a educação nacional são as modalidades remotas. Com isso, para se obter insumos de indicadores para observação da realidade, utilizou-se o instrumento intitulado "Questionário - Educação das Relações Étnicoraciais e história e cultura afro-brasileira, africana e indígena" que foi aplicado por meio de um questionário on-line distribuído a professores que 
atuam na cidade de Araguari e região através de email e WhatsApp. 0 formulário foi aplicado de 05 a 13 de maio de 2020, tendo como respondentes 31 profissionais, sendo suas respostas anônimas. 0 perfil dos respondentes ao questionário foi:

\section{Faixa etária:}

- 12 entre 20 e 35 anos (38,7\%);

- 11 entre 36 e 50 anos (35,5\%);

- 8 entre 51 e 65 anos $(25,8 \%)$.

Sexo:

- 29 feminino $(93,5 \%)$

- 2 masculino (6,5\%).

Nível de formação:

- 16 graduação $(51,1 \%)$;

- 14 especialização $(45,7 \%)$;

- 1 mestrado (3,2\%).

\section{Atuação em instituições educacionais de que segmento:}

- 16 Públicas Municipais (51,1\%);

- 6 Públicas Estaduais (19,9\%);

- 9 Instituições Privadas/particulares (29\%).

Partindo da análise da pesquisa realizada, considerando as respostas dos participantes, identificou-se que os docentes não estão preparados para abordar e atuar nas questões étnico raciais. Na tentativa de minimizar esse problema, por falta de experiência e/ou pelo fato de indicarem que a temática das relações étnico raciais sempre estar "em desenvolvimento na escola", levanta-se o questionamento: Será que o tema somente é citado no projeto político pedagógico das escolas, porém, efetivamente, não sai do papel, ou ainda, é trabalhado somente em datas comemorativas sazonais?

Fica explicito que a abordagem do tema nas escolas é escassa, sendo insuficiente no quesito relacionado ao papel do educados em buscar meios, através de bibliografia, sobre as questões étnicas e raciais. A partir dessas pesquisas, deve eleger temas para discussão em grupo de estudos e ainda fomentar a criação de cursos para se atualizarem, repassando para seus alunos e para comunidade escolar como um todo, os saberes e conhecimentos sobre a história para que possam se aprofundar nas causas e consequências da dispersão dos africanos e indígenas no Brasil e no mundo.

\section{JUSTIFICATIVA}

Estudos como os de Piza (2000 apud Bento, 2002, p. 49) e de Tatum (2003, p. 93-95), realizados em contextos diferentes, são esclarecedores quando apresentam que pessoas brancas não costumam sentir-se pertencentes a um grupo étnico-racial, ou dão pouca atenção para sua identidade racial, uma vez que ser e viver como brancos é a norma aceita pela sociedade.

Segundo Piza (2000, apud Bento 2002, p. 49), "aspectos da atitude branca - neutra, não reconhecível, negada, expurgada do seu potencial político - envolvem séculos de pensamentos e atos racistas". Em consonância, Silva (2007, p. 492) ressalta que "pessoas criadas numa sociedade racializada têm uma visão de mundo marcada por essa racialidade".

Muito se tem discutido acerca das relações étnicoraciais e da necessidade de erradicar o preconceito, o racismo ou qualquer outra forma de discriminação racial e cultural. Apesar de muitos acreditarem que atualmente não exista discriminação, ou ocultarem a realidade que nos cerca para se refutar, não se pode deixar tal debate de lado, pois a única maneira de abordar a temática com responsabilidade é pelo aprofundamento no contexto originário e de evolução, trazendo à tona a diversidade que acomete a realidade.

É importante tratar o tema com os alunos desde os anos iniciais de ensino, não somente celebrar em datas sazonais, mas reforçar a importância durante todo o ano letivo, prezando pela construção e formação de cidadãos conscientes de seus direitos e deveres perante uma sociedade abastada de diversidade racial e cultural.

Ao arrazoar o tema central deste artigo a critério das competências e habilidades de docentes na abordagem das relações étnico-raciais em suas práticas de sala de aula, salientou-se que o tema é tratado superficialmente, não ficando conveniente ao que dispõe a LDB (Lei de Diretrizes e Bases da Educação Nacional) e a Lei 10.639/03. A fim de justificar tal a afirmação tem-se os indicativos 
destacados em dados indicados na observação da realidade.

No Brasil a discriminação já é tratada do ponto de vista jurídico com total rigor, dispondo de penalização severa, em que os infratores são submetidos a reclusão, conforme trata a Lei no 7.716, de 5 de janeiro de 1989 .

Logo evidencia-se indícios de muitos docentes não trabalharem o tema de maneira aprofundada, por não vivenciarem ativamente $o$ contexto da comunidade escolar a qual atua profissionalmente.

Frente esta realidade, o artificio de maior relevância é a educação, e é o docente o sujeito ativo capaz de disseminar estruturação de alunos conscientes e agentes empáticos da diversidade racial e cultural da qual compõe.

\section{4}

\section{PROBLEMA}

Como minimizar o despreparo dos docentes para atuar de forma contínua e a aprofundada o tema étnico-raciais e história e cultura afro-brasileira?

Este artigo enfoca o evidente despreparo, buscando identificar os causadores dessa sequência de atitudes que não disparam relevância no aprendizado dos alunos referentes a temática e os motivos de não existir incentivadores e/ou motivação da parte docente para trabalhar de forma contínua um tema que contribui como alicerce para construção de cidadãos e de uma sociedade com mais equidade no que tange a direitos e deveres relacionados a diversidade racial e cultural.

A educação das relações étnico-raciais deve ser conduzida, tendo-se como referências os seguintes princípios (BRASIL, 2004, p. 17): "consciência política e histórica da diversidade; fortalecimento de identidades e de direitos; ações de combate ao racismo e a discriminações".

Para desencadear, executar e avaliar o processo de educação das relações étnicoraciais é preciso que se compreenda como os processos de aprender e de ensinar têm se constituído entre nós ao longo dos 507 anos de história de formação da nação. (SILVA, 2007, p. 490)

Apesar dos variados entendimentos docentes para tratar a temática proposta em sala de aula, o que deve ficar, é que para tal, se faz de extrema importância o embasamento teórico, um conhecimento prévio a respeito da história que o faça sentir pertencente dessa diversidade, e o leve a contextualizá-la para a realidade atual ressignificando os valores, as tradições e tudo o que possa contribuir para $o$ entendimento $e$ conscientização.

Mediante a ferramenta de pesquisa aplicada, constatou-se que a maior porcentagem de resposta se aplica a alternativa de "trabalho em desenvolvimento na minha escola".

A partir dessa realidade observada, questionamentos acerca das respostas floresceram, na tentativa de respostas para compreender a escassez da temática durante todo o ano letivo:

- Qual fator gerador para abordar a temática?

- De que maneira a temática está em andamento na escola?

- Quais são os objetivos ao ensinar a temática?

- Qual seu nível de conhecimento para abordar a temática?

Assim, as explanações seguintes pretendem explorar uma inquirição de hipóteses de soluções capazes de abarcar alternativas para evolução da temática com os alunos ensino fundamental nas escolas públicas da cidade de Araguari/MG.

\section{PONTOS-CHAVE}

As ações pedagógicas voltadas para o cumprimento da Lei no $10.639 / 03$ e suas formas de regulamentação se colocam nesse campo. A sanção de tal legislação significa uma mudança não só nas práticas e nas políticas, mas também no imaginário pedagógico e na sua relação com o diverso.

Podemos afirmar que temos uma cultura de discriminação racial. Cultura, como a define Geertz (2008, p. 102), compreende um padrão de significados transmitidos historicamente, um sistema de concepções herdadas expressas em formas simbólicas por meio das quais nos comunicamos, produzimos e reproduzimos conhecimentos e atividades em relação à vida. 
Os causadores iminentes coesos a problemática em matéria percebidos acometem-se a falta de acessibilidade à materiais de pesquisa de ordem virtual e/ou bibliográfica que tratem o tema com seriedade e deixe de lado estereótipos desnecessários para eficácia da aprendizagem.

Outro ponto destacado como problema é a frequência que o tema é trabalhado pelos professores, os disparadores que o acometem, a falta de interesse e preparo ou limitação de tempo em virtude de trabalharem em diversos turnos.

Considerando os fatores condicionantes aqui levantados, para melhor entendimento da aparição dos respectivos problemas e ensejando a descoberta de resolução, expõe-se os fatores que se interferem para que o problema exista, são eles:

- Falta de acesso à materiais referentes ao tema, tanto digitais, quanto de acervo bibliográfico;

- Insuficiência de tempo para confecção e preparação de materiais para aulas que explorem mais profundamente a temática;

- Omissão de interesse em trabalhar o tema de maneira significativa.

A partir desses pontos-chave buscou-se 0 aprofundamento teórico para melhor compreensão da abordagem referente ao tema pesquisado.

\section{TEORIZAÇÃO}

O amparo teórico contribui para respaldar os princípios de estudos dos pontos-chave, por conseguinte, guia às hipóteses de solução para o problema indicado. Sendo estes proferidos por meio de livros disponíveis em bibliotecas virtuais e artigos científicos contidos em repositórios online.

Gonçalves (1985, p. 1 - 250) já chamava a atenção, na década de 80, para o lugar ocupado pelo silêncio sobre a questão racial na escola. Na sua dissertação de mestrado, intitulada $O$ silêncio - um ritual pedagógico a favor da discriminação racial: um estudo acerca da discriminação racial como fator de seletividade na escola pública de primeiro grau: 1ㅇ a 4a série, o autor acham a atenção para algo mais profundo. Esse panorama da década de 80 narra cristalinamente a educação no Brasil e ainda leva a perceber sua marca existente na sociedade.

(...) o livro didático é um importante veículo portador de um sistema de valores, de uma ideologia, de uma cultura. Várias pesquisas demonstram como textos e ilustrações de obras didáticas transmitem estereótipos e valores dos grupos dominantes, generalizando temas como família, etnia, de acordo com os preceitos da sociedade branca burguesa (BITTENCOURT 2007, p. 47)

Muito se discute entre os docentes sobre a relevância da escolha do material didático para o ensino aprendizagem dos alunos, porém o professor não deve ficar limitado somente a esses conteúdos. Faz-se necessário convergir com a importância do tema para o desenvolvimento dos alunos perante a sociedade e, como cidadãos, apropriar-se de mais formações no que concerne determinados assuntos, tais como o das relações étnicas.

De forma mais geral essa é uma realidade no país. A Lei 11.645/08 determina que o conteúdo programático a que se refere a lei incluirá diversos aspectos da história e da cultura que caracterizam a formação da população brasileira, a partir desses dois grupos étnicos, tais como o estudo da história da África e dos africanos, a luta dos negros e dos povos indígenas no Brasil, a cultura negra e indígena brasileira e o negro e o índio na formação da sociedade nacional, resgatando as suas contribuições nas áreas social, econômica e política, pertinentes à história do Brasil.

Em consonância, ressalta-se que os conteúdos referentes à história e cultura afro-brasileira e dos povos indígenas brasileiros devem ser ministrados no âmbito de todo o currículo escolar, em especial nas áreas de educação artística e de literatura e história brasileiras.

6.1 Falta de acesso a materiais referentes ao tema, tanto digitais, quanto de acervo bibliográfico

A LDB remete que a formação continuada, bem como sua capacitação, poderá utilizar recursos e tecnologias de educação a distância.

Conforme apontado no questionário aplicado, os professores sinalizam que desconhecem modos que 
incrementem o ensino com relação ao tema abordado, limitando sua abordagem em datas sazonais.

O aprofundamento referente a $11.645 / 08$ e sua apropriação para aplicação na docência não é tema do aperfeiçoamento continuado, mas sim o modo como deve ser construído o currículo.

Repensar a formação do professor significa subsidiar com conhecimentos, práticas e políticas os processos de formação inicial e continuada. Atualmente a formação de professores e a capacitação em serviço vivenciam uma realidade totalmente diferente das práticas previstas na legislação. Uma formação continuada que visa valorizar o professor como sujeito crítico-reflexivo, aponta para a relevância da "reflexão na ação, da reflexão sobre a ação e da reflexão sobre a reflexão na ação." (PIMENTA; GHEDIN, 2002, p. 29).

6.2 Insuficiência de tempo para confecção e preparação de materiais para aulas que explorem mais profundamente a temática

Planejamento é um processo de previsão de necessidades e racionalização de emprego dos meios materiais e dos recursos humanos disponíveis, a fim de alcançar objetivos concretos, em prazos determinados e em etapas definidas, a partir do conhecimento e avaliação científica da situação original. (MARTINEZ, 1977, p. 11)

Em síntese, fica explícito que o planejamento precisa ser uma prática constante no trabalho do professor e ainda o envolvimento com pais e comunidade como fundamental na educação da criança.

A ação de planejar, portanto, não se reduz ao simples preenchimento de formulários para controle administrativo, é, antes, a atividade consciente da previsão das ações político - pedagógicas, e tendo como referência permanente às situações didáticas concretas (isto é, a problemática social, econômica, política e cultural) que envolve a escola, os professores, os alunos, os pais, a comunidade, que integram o processo de ensino. (LIBÂNEO, 1994, p. 22)

Freire (1987, p. 60) traz sua contribuição à preparação do material pedagógico ressaltando que: "o espaço pedagógico é um texto para ser constantemente lido, interpretado, escrito e reescrito"

Respaldado por este pensamento, compreende-se, pelo exposto, que os fazeres na formação continuada, devem estar presentes na rotina do docente, assim como os demais hábitos diários de sua atuação.

\subsection{Omissão de interesse em trabalhar o tema de maneira significativa}

O acervo de materiais didáticos sobre a temática indígena é escasso nas escolas públicas, partes pela baixa publicação referente a esse tema, mas também pelo baixo interesse das entidades governamentais. Comumente se encontram nos livros didáticos afirmações contra o racismo e o preconceito, porém ao analisar atentamente esses materiais, percebe-se que existe uma dificuldade em abordar as diferenças étnicas na sociedade brasileira atual. $O$ que geralmente se faz, principalmente com relação ao índio, é deixá-lo no passado.

“É preocupante o fato dos livros didáticos no Brasil não trazerem informações como está e tampouco representarem os negros e os índios como um grupo participante na construção da história e da cultura da nação brasileira" (BRASIL, 2004, p. 18). Dessa reflexão dá-se início a um cenário de racismo silenciado dentro das salas de aula, legitimado pelos livros didáticos.

Munganga (2005, 204 p.), em seu livro intitulado Superando o racismo na escola, aponta a conivência do professor perante as situações de preconceito e racismo como o mal maior dentro da escola. Em virtude da sua formação o professor tende a ignorar situações de racismo em que sua intervenção seria fundamental para um novo olhar sobre a diversidade e para a valorização de outras culturas. Faz-se relevante que os professores apresentem aos alunos a riqueza cultural em se conviver na diversidade e combater o racismo nas salas de aula.

É evidente que as exigências atuais impulsionam uma sequência de ações e os docentes devem valerse de criatividade para a realização de seu planejamento de aula, pois existe uma variedade de recursos que podem ser utilizados em colaboração com o livro didático no desenvolvimento de suas 
atividades. Entre esses recursos destaca-se o uso de músicas, filmes, vídeos, depoimentos, visitas, histórias em quadrinhos, entre outros.

A teorização, realizada com o objetivo de buscar fundamentação teórica para o problema em destaque, com um embasamento mais profundo acerca dos pontos-chave levantados, tornou mais explícita a necessidade de fomentar meios mais acessíveis para formação continuada dos docentes. Em síntese, constituiu-se na etapa da teorização uma condição básica para a apresentação das hipóteses de solução dadas ao problema eleito para o presente estudo.

\section{HIPÓTESES DE SOLUÇÃO}

A reflexão dos aspectos desenvolvidos na teorização, realizada com base na literatura selecionada, possibilitou, apresentar diversas alternativas que contribuem para a solução do problema estudado:

- Fortalecer pensamento crítico reflexivo do docente;

- Desenvolver habilidades para explorar o tema supracitado;

- Ofertar oficinas de formação continuada acessíveis;

- Realizar visitações a museus, vilas indígenas, e outros;

- Elaborar o cronograma de atividades para ser desenvolvido junto projeto políticopedagógico para ser trabalhado durante todo o ano letivo;

- Incentivar a pesquisa e criatividade alinhada às metodologias ativas.

Em síntese, constituiu-se na etapa da teorização uma condição básica para a apresentação das hipóteses de solução dadas ao problema eleito para o presente estudo.

Ao analisar essas perspectivas, identificou-se como possibilidades de aplicação mais adequadas com as condições atuais do contexto regional, uma oficina específica com relação ao tema direcionado aos docentes tendo por objetivo abordar as premissas de planejamento de aulas, fontes para pesquisa, criatividade, utilização de metodologias ativas, entre outros.

\section{APLICAÇÃO À REALIDADE}

A partir da análise das hipóteses de solução, de uma reflexão acerca dos fatores imediatos e das condicionantes maiores, bem como do contexto no qual se encontra o problema em questão, foi possível eleger algumas contribuições para a solução do problema apresentado com o objetivo de intervir na realidade de modo a buscar o atendimento às necessidades da formação continuada e ainda viabilizar acessibilidade para prática significativa da execução de cursos que norteiam o planejamento de aulas e prática docente com a utilização de metodologias ativas.

A proposta do projeto fica a disposição para as instituições de ensino fundamental do município de Araguari-MG, sendo estruturada para acontecer de acordo com datas estabelecidas em cronograma acordado com elas, compelidas de determinas datas e horários para as seguintes atividades:

- Levantamento de necessidades;

- Validação da oficina com a coordenadora pedagógica da instituição;

- Entrega do convite aos professores;

- Realização de oficina sobre as metodologias ativas.

No encerramento da oficina será aberto espaço para os docentes compartilharem suas percepções e relatos acerca da ação a ser realizada.

Ao desenvolver este artigo seus autores se depararam com aprendizados que instigaram a busca no aprofundamento sobre o contexto da educação indígena. Alguns questionamentos em relação à educação por eles recebida foram levantados e ressignificados, trazendo profundas e importantes visões sobre o constructo social referente aos povos indígenas.

Entende-se que o assunto tratado na realização desse artigo ainda deve ser fomentado, de forma contínua, para que a educação étnico-racial seja uma realidade nas escolas, não apenas em datas comemorativas. 
9

\section{CONSIDERAÇÕES FINAIS}

O tema pesquisado é de fundamental importância para o ensino-aprendizagem dos alunos, e por meio de seu representante em sala de aula - o docente, fica a responsabilidade de formar o seu aluno para o exercício da cidadania e essa tarefa pode perfeitamente ser realizada amparada na história de seu país.

No entanto, o objetivo deste é propor meios para docentes buscar embasamento na preparação de suas aulas garantindo um ensino, e aprendizagem efetivos a seus alunos no que se refere à temática das relações étnico-raciais.

Dessa forma, conclui-se que os fazeres do docente tanto na sua prática em sala de aula como na formação continuada, devem se fazer presentes em sua rotina de atuação profissional.

\section{0}

\section{REFERÊNCIAS}

698 Modos de fazer: caderno de atividades, saberes e fazeres. Org. Ana Paula Brandão. Rio de Janeiro: Fundação Roberto Marinho, 2010.

BENTO, Maria Aparecida da Silva. Racialidade e produção do conhecimento. In: SEYFERTH et al. Racismo no Brasil. São Paulo: ABONG, Ação Educativa, ANPED, 2002. p. 45-52.

BITTENCOURT, C. Identidades e Ensino de História no Brasil. In. CARRETERO, Mario et al. Ensino da História e Memória Coletiva. Porto Alegre: ARTMED, 2007. p. 33-52.

BROSSARD, Paulo. LEI № 7.716, DE 5 DE JANEIRO DE 1989. 1989. Disponível em:

http://www.planalto.gov.br/ccivil 03/leis/17716.ht m. Acesso em: 23 maio 2020.

BUARQUE, Cristovam Ricardo Cavalcanti. LEI No 10.639, DE 9 DE JANEIRO DE 2003. 2003.

Disponível em:

http://www.planalto.gov.br/ccivil 03/leis/2003/l10 .639.htm. Acesso em: 22 maio 2020.

BRASIL. Guia de livros didáticos PNLD 2011: Língua Estrangeira Moderna. Brasília: Ministério da Educação, Secretaria de Educação Básica, 2010.
Diretrizes Curriculares Nacionais para a Educação das Relações Étnico Raciais e para o ensino de História e Cultura Afro-Brasileira e Africana (Parecer No. CNE/CP 3/2004). MEC Ministério da Educação: Conselho Nacional de Educação. Brasília: 10/03/2004, p.17. 2004.

FREIRE, Paulo. Pedagogia do oprimido. 17ạ ed. Rio de Janeiro: Paz e Terra, 1987.

GEERTZ, Clifford. A interpretação das culturas. Rio de Janeiro: LCT, 2008. Instituto Brasileiro de Geografia e Estatística - IBGE. Síntese de indicadores sociais: uma análise das condições de vida da população brasileira 2010. Disponível em: https://biblioteca.ibge.gov.br/visualizacao/livros/liv 101629.pdf. Acesso em 20 de maio 2020.

GONÇALVES, Luiz Alberto Oliveira. O silêncio: um ritual pedagógico a favor da discriminação racial: um estudo acerca da discriminação racial como fator de seletividade na escola pública de primeiro grau: 10 a 4a série. 1985, 250 p. (Dissertação, mestrado em educação). Programa de pósgraduação em educação conhecimento e inclusão social. Universidade Federal de Minas Gerais, Belo Horizonte, 1985.

HADDAD, Fernando (ed.). LEI № 11.645, DE 10 MARÇO DE 2008. 2008. Disponível em: http://www.planalto.gov.br/ccivil 03/ Ato20072010/2008/Lei/L11645.htm. Acesso em: 17 jun. 2020.

LIBÂNEO, José Carlos. Didática. São Paulo. Editora Cortez. 1994.

MARTINEZ, M.J. LAHONE, C.O. Planejamento escolar. São Paulo: Saraiva, 1977.

MUNANGA, Kabengele (Org.). Superando o racismo na escola. Brasília: Ministério da Educação, Secretaria de Educação Continuada, Alfabetização e Diversidade, 2005. 204 p.

PIMENTA, S.G.; GHEDIN, E. (Orgs.). Professor reflexivo no Brasil: gênese e crítica de um conceito. 2. ed. São Paulo: Cortez, 2002. Disponível

SILVA, Petronilha Beatriz. Aprender, ensinar e relações étnico-raciais no Brasil Educação. vol. XXX, núm. 63, setembro-dezembro, 2007, p. 489- 
506. Pontifícia Universidade Católica do Rio Grande do Sul Porto Alegre, Brasil.

SOUZA, Paulo Renato. LEI № 9.394, DE 20 DE

DEZEMBRO DE 1996: estabelece as diretrizes e

bases da educação nacional. Estabelece as

diretrizes e bases da educação nacional.1996.

Disponível em:

http://www.planalto.gov.br/ccivil 03/leis/19394.ht

m. Acesso em: 23 maio 2020.

TATUM, Beverly D. Why are all Black kidstoghether in the Cafeteria? And another conversations about race. New York: Basic Books, 2003. 